\title{
Las relaciones históricas entre España y Polonia ${ }^{\star}$ \\ ZBIGNIEW GÓRALSKI Universidad de Lublin (Polonia)
}

La distancia que separa ambos países provoca que España sea para un polaco medio, un país exótico. No existían y, si así puede decirse, no existen, unos asuntos comunes, una misma cultura, ni contactos en la fe, a pesar de que ésta sea la misma: sencillamente siempre se estaba demasiado lejos. Por eso los peregrinos polacos se encaminaron desde la Edad Media hasta el siglo XVII, en su mayoría, a Occidente, pero a Compostela no llegaban más que en casos contados. Las miras de los numerosos viajes científicos de la juventud polaca, durante los siglos XVI al XVIII, se dirigieron a países como Alemania, Francia e Italia y, durante la segunda mitad del siglo XVIII, particularmente, a Inglaterra, cuyo sistema político fue tenido como modélico. Parece como si los $\mathrm{Pi}$ rinéos hubieran actuado como una barrera entre los dos países.

Por entonces España era casi una desconocida, por lo que siempre suscitaba fascinación. A pesar de todo, un polaco medio supo y sabe qué es España, dónde está y con qué problemas se enfrenta. La literatura española es leída y Cervantes considerado un canon literario que hay que conocer. Antes de la Segunda Guerra Mundial fueron editadas varias antologías del Quijote de Cervantes dedicadas a los niños. La sociedad polaca siguió con viva atención la Guerra Civil española.

Es muy significativo que estos contactos históricos entre España y Polonia comenzasen muy tempranamente. En el primer período de su existencia, en los siglos X y XI, Polonia no tuvo cronistas propios: éstos aparecieron por vez primera en el siglo XIII. Todo lo que sabemos de esta época procede de cronistas extranjeros o de comerciantes, que llegaron a Polonia dejando con frecuencia la descripción de lo que vieron y experimentaron en su recorrido. Resulta curioso que el primer relato sobre la Polonia histórica provenga de un español, un comerciante,

^ Conferencia pronunciada en 1987 en la Casa de la Cultura de Cádiz. 
Ibrahim Ibn Jaime, un judío de Tortosa, establecido en Polonia. Este relato, que describe la corte del príncipe polaco, el país y sus habitantes, fue también para España la primera información que tuvo acerca de Polonia.

Fue éste, naturalmente, un contacto no oficial. El primero con este carácter tuvo lugar en el año 1152 ó 1153, cuando el rey de Castilla y León, don Alfonso VII el Emperador, contrajo matrimonio con una princesa polaca, Rica o Rixa, hija del Gran Príncipe Ladislao II de Polonia, "el Desterrado". No se sabe cómo don Alfonso conoció a Rica. Quizás actuase como mediadora la corte imperial alemana, con la que Ladislao mantenía vivos contactos, y donde había residido tras haber sido expulsado de Polonia por sus hermanos. Rica dejó un buen recuerdo en Castilla al proteger a la Iglesia y socorrer a muchos monasterios. Desde la muerte de su marido, las crónicas no dirán nada más de Rica.

Durante este tiempo existió otro contacto más entre los dos estados, en este caso por iniciativa española, muy poco conocido y mencionado. Se trata de la cristianización de la Pomerania Occidental conquistada por Polonia a inicios del siglo XII. Se trataba de territorios eslavos que ya los polacos habían cristianizado a comienzos del siglo XI, pero esta acción quedó interrumpida rápidamente a consecuencia de las desfavorables circunstancias políticas en que Polonia se vio envuelta. En 1122 y por medio de una campaña militar, la Pomerania occidental quedó sometida a Polonia, reanudándose entonces la evangelización. La primera etapa de esta operación fue dirigida por un benedictino español, de nombre Bernardo, del que sabemos muy poco. Ignoramos de dónde procedía, cuándo y por qué dejó España. Es probable que se ordenara en Italia, siendo en ella nombrado también obispo de una diócesis que nos es desconocida, en el puesto del prelado anterior, que había sido depuesto por el papa. La diócesis se encontraba por entonces dividida en partidos, uno de los cuales apoyaba al antiguo obispo. A pesar de todo, Bernardo debió resignarse, decidiendo ocuparse de las tareas evangelizadoras en medio de los pueblos eslavos, según la regla trazada por los eremitas italianos.

Bernardo llegó a Polonia alrededor del año 1120, estableciéndose en el monasterio benedictino de Kazimierz, en la Gran Polonia. Allí estableció contacto con la corte del Gran Príncipe de Polonia (en este país no existía todavía rey, sino un príncipe de rango superior), por medio del cual fue enviado a la Pomerania occidental con la misión de convertir a sus habitantes. Pero Bernardo partió con muy escasos medios, ya que solamente le acompañaron dos compañeros, y carecía de recursos económicos suficientes, por lo que su tarea terminaría fracasando. Probablemente llegó hasta la isla de Wolin, donde sería ridiculizado y ex- 
pulsado. Los pomeranos lo habían rechazado afirmando que Dios no podía tener unos representantes tan pobres como ellos, que apenas podían ofrecerles nada de interés a hombres ricos como ellos. Efectivamente, la población de Pomerania era relativamente acomodada y se dedicaba al comercio con otros países bálticos. Sólo cuando, en 1124, llegó a esta región el obispo alemán Otto de Bamberg, trayendo consigo un nutrido séquito y riquezas, Pomerania pudo ser finalmente convertida.

Bernardo regresaría con seguridad a Polonia. Quizás lo había salvado el miedo que los habitantes de esta zona tenían a su protector, el Gran Príncipe de Polonia: de esta manera no llegaría a tener un destino similar al de San Adalberto, evangelizador de Prusia a finales del siglo $\mathrm{X}$, que había sido asesinado por los paganos prusianos. Tras su regreso, Bernardo sería enviado de nuevo por el Gran Príncipe como embajador a Bamberg. Se supone que lo nombró primer obispo de Lubusz, cuya diócesis fue fundada por Polonia en el año 1124. Tras estos datos, no poseemos más noticias de Bernardo, que se supone moriría en torno al año 1125.

En la Pomerania oriental, concretamente en Gdànsk, actuaría también durante un breve período de tiempo (unos 25 años), la Orden de Calatrava. Esta había llegado a principios del siglo XII por medio de la abadía cisterciense de Oliva, instalada cerca de la referida ciudad; por lo cual la orden adoptaría la regla de San Bernardo. Sus caballeros se establecieron en la localidad de Tymawa, cerca de Gniew, con la misión de defender las fronteras polacas contra las incursiones de los paganos prusianos, así como de cristianizarlos. Los caballeros de Calatrava abandonarían la región hacia 1230, siendo sustituidos probablemente en 1226 por la Orden Teutónica, con la que Polonia guerrearía después muy duramente, siendo los creadores del estado prusiano, de tanta importancia en la historia de la Europa central y oriental casi hasta nuestros días.

Durante los dos siglos siguientes no tenemos noticia de las relaciones entre España y Polonia, a excepción de las que establecieron los peregrinos polacos llegados a Santiago de Compostela, que, sin embargo, no llegarían a alcanzar en todo el siglo XIV el número de 120, cifra por lo tanto muy poco importante.

El primer encuentro hispano-polaco oficial y directo tendría lugar durante el Concilio de Constanza en 1415. Ambos países defenderían la necesidad de evangelizar a los pueblos paganos con medidas pacíficas y no violentas: pero fue ésta una voz aislada y sin consecuencias, aunque los dos países apoyaran esta línea humanitaria de tanta trascendencia histórica en el delicado asunto de la evangelización.

A finales de este siglo, en 1490, llegaría a España, estableciéndose en. Sevilla, el eminente tipógrafo Estanislao el Polaco. Desgraciadamen- 
te, no conocemos su apellido ni su lugar de origen, si bien puede pensarse que fuera silesiano y estudiara en la Universidad de Cracovia. Después, junto a su compañero, el alemán Ungut, llegaron a España procedentes de Nápoles para recorrerla (procedimiento bastante frecuente en aquellos tiempos). Su primer libro se editaría en Sevilla en 1491, y esta actividad tipográfica se prolongó durante 14 años. Durante este período de tiempo llegarían a editar 111 impresos conocidos, aunque probablemente fuesen más, dentro de un nivel técnico muy elevado para la época. Abarcarían temas muy diferentes: Ciencia, Religión y Teología, Derecho, Filosofía, Medicina e Historia, editando también obras antiguas y clásicas (la primera edición española del "Decamerón» de Boccaccio y "La Celestina» de Fernando de Rojas). A continuación, Estanislao el Polaco establecería una segunda tipografía en Alcalá de Henares, llegando a ser un eminente personaje de la cultura española, a caballo entre los siglos XV y XVI. En cuanto a su taller tipográfico, sabemos que, tras su muerte, fue trasladado a México.

El siglo XVI contemplará un desarrollo muy rápido e intenso de las relaciones diplomáticas entre España y Polonia. Pero éstas, más que entre estados, tendrían lugar entre personalidades: así, con el rey de España, de la familia de los Habsburgo, lo que supuso la participación política de Polonia en la diplomacia de éste. Tales relaciones fueron el resultado del matrimonio, en 1518, del rey de Polonia, Segismundo el Viejo, con una princesa nacida en Bari, Bona Sforza, hija de Isabel de Aragón y de Gian Galeazzo Sforza. Bari había pertenecido a España y Bona, por lo tanto, había sido educada en un ambiente español, aunque no sabemos si ella llegó a conocer su lengua (en Polonia utilizó el italiano y el latín).

El asunto de estos contactos diplomáticos fue la dote de Bona, formada territorialmente por algunos principados en Apulia y Calabria, junto con Bari y Rossano, heredados de su madre. Estos pertenecían al reino de Nápoles, y pasaron junto con éste a manos de Carlos I. Bona necesitaba por ello la investidura de sus bienes, pero el futuro emperador lo dilataba. Por este medio pudo presionar sobre Polonia para inclinarla hacia una política favorable a los intereses de los Habsburgos, y recibir así ayuda para la obtención del trono imperial. Carlos aguardaría durante seis años, hasta 1524, para conceder la referida investidura, justo en momentos difíciles para su política italiana (ocupación de Milán por los franceses). Asunto de litigio fue también un tributo guerrero (adoha), que el virrey de Nápoles había cobrado de forma ilegal.

El negociador por parte polaca de todos estos asuntos fue un eminente diplomático, a la par que cualificado personaje del Renacimiento en Polonia y Europa, Juan Dantisco, poeta (escribió en latín) y conse- 
jero del rey de Polonia. Había nacido en Alemania, pero tras vivir varios años en Polonia se fue napolizando; hasta convertirse en un verdadero patriota. Vino a España en tres ocasiones, entre los años 1518 y 1529, residiendo durante largo tiempo en la corte imperial de Toledo y en la ciudad de Valladolid. Sin merma de sus obligaciones oficiales, llevó en España una vida despreocupada, haciéndose amigo de un tal Hernán Cortés, con quien visitaría las alegres posadas peninsulares. Dejó aquí una hija ilegítima, en tanto que uno de sus nietos llegaría a ser consejero y confesor de la misma Santa Teresa de Jesús.

En los asuntos principales, sin embargo, sus resultados fueron escasos, pues tan sólo resolvería el contencioso de la investidura de la reina Bona, gracias a la cual fue condecorado por el rey de Polonia con el Toisón de Oro. Pero Bona no obtendría las sumas que le correspondían en concepto de dote y atrasos de rentas desde 1504, por sus bienes en el reino de Nápoles. A Carlos siempre le faltaba el dinero necesario para sus incesantes guerras; razón por la que no pudo atender al mismo tiempo la demanda de Bona. A pesar de todo, en sus relaciones con la corte española, Dantisco llegó a contar para su misión diplomática con la ayuda del influyente canciller Gattinara.

La opinión de Dantisco sobre España no fue muy favorable, pues la consideraba un lugar de destierro, frío, de deficientes artes culinarias, echando de menos su querida Polonia. Estas opiniones de Dantisco fueron correspondidas por parte española, ya que se sospechaba de él, lo que por lo demás era incierto, que actuaba en favor de Francia y, por lo tanto, en contra de España. Ello se dio a entender, especialmente, durante su tercer viaje diplomático en 1523. El propio Dantisco lo cuenta por extenso en su correspondencia, tanto privada como diplomática, donde podemos hallar también descripciones de España, de sus costumbres, de sus imágenes sobre la vida cotidiana, todas ellas poco explotadas por los investigadores en la actualidad.

Dantisco tuvo también problemas con la Inquisición española, pues no en vano coleccionó diversas historietas sobre el clero de la manera del «Decamerón». Estaba acostumbrado al uso de Polonia, donde estas cosas no irritaban a nadie y los eclesiásticos vivían muy libremente,' a la manera italiana. Dantisco lograría burlar la persecución, mientras que sus dos servidores debieron pasar cinco meses en una prisión inquisitorial; pero a nuestro hombre no le quedarían, después de la experiencia, más ganas de historias. Poco después, Dantisco sería de nuevo acusado por la Inquisición de apoyar la Reforma, aunque tales cargos fueran falsos. Es verdad que Dantisco mantuvo contactos en Alemania con Lutero y Melanchton, pero no por ello favorecería el luteranismo, si bien se mostró tolerante con el mismo en Ermland y Gdànsk. La persecu- 
ción, pues, se debió a las intrigas del virrey de Nápoles, quien de este modo se defendería contra las pretensiones financieras del diplomático, apartándole del lado del Emperador.

En 1523, Dantisco regresaría a Polonia sin apenas solucionar nada, incluida la dote para la reina Bona, si bien consiguió apartarse de la agitada vida que había llevado en España. Por sus méritos en el campo diplomático recibiría el obispado de Ermland, donde fue superior de Copérnico, que vivió como canónigo en Frombork, capital de dicho obispado. Por lo demás, Dantisco prestaría su apoyo a Copérnico y a su obra astronómica.

A pesar de todo, se puede considerar la misión del "polaco» como exitosa para las relaciones entre Polonia y España. Fue él, principalmente, el primer embajador estable de Polonia en España, llevando hasta la primera el conocimiento de la segunda, en especial de la cultura y, sobre todo, de la literatura españolas, así como de sus avances geográficos. Además, Dantisco continuaría su amistad con Hernán Cortes una vez llegado a Polonia, recibiendo de él los relatos de su conquista y divulgándolos en su país.

La segunda fase de las relaciones diplomáticas entre los dos países tendría lugar después de la muerte de Bona en 1557. Esta había dejado Polonia el año anterior, llevando consigo todas sus propiedades personales, así como una elevada suma de 430.000 ducados, que, en seguida, prestó al rey Felipe II. Los diplomáticos polacos tuvieron ahora como misión el recuperar esta suma, al igual que la herencia, en especial los principados de Bari y Rossano, que prácticamente habían pasado a España. Durante su vida $(1550,1553,1554)$, Carlos I procuró que Bona cediera su patrimonio italiano al futuro Felipe II, a lo que ésta se opuso. Poco más tarde moría envenenada por un agente de los Habsburgo, no sin antes haberla obligado a firmar la cesión de estos territorios en su testamento. El asunto estaba perdido de antemano para Polonia: si Carlos, como Emperador, hubo de negociar con Polonia los asuntos relacionados con checos y húngaros, no ocurriría lo mismo con su hijo $\mathrm{Fe}-$ lipe, al no ser éste emperador y no tener asuntos directamente relacionados con Polonia que resolver. No existió, pues, ninguna presión que obligase a devolver tan inmenso préstamo, por lo que la actividad de los diplomáticos polacos (Wojciech Kryski, Stanislaw Krzimuski, Piotr Barzy y Piotr Dunin Wolski), que durante los años 1558 a 1573 residieron ininterrumpidamente en la corte de Felipe II, quedó sin efecto.

Sólo obtuvieron un pequeño número de bienes y una escasa parte de la suma prestada, después de largas y embarazosas negociaciones. Polonia reclamaría las llamadas "sumas napolitanas» aún en el siglo XVIII, hasta los tiempos de la pérdida de su independencia, e incluso, más tar- 
de, una vez constituido en 1815 el reino de Polonia, aunque subordinado a Rusia.

Durante el gobierno de Felipe II comenzará una época de intenso comercio entre Polonia y los Países Bajos españoles, sirviendo como intermediario el puerto de Gdànsk. Sin embargo, otro puerto polaco, Elblag, según se cree, no participó en ello. Se exportaba desde Polonia sobre todo cereales, madera (según decían, los pinos polacos servían para mástiles de barcos, dado que eran altos y rectos), además de lino, cáñamo y otros productos agrarios. Las dimensiones de este comercio fueron inmensas. Las mercancías pasaron a Gdànsk a través de los ríos, y hasta hoy, en algunas ciudades, han quedado graneros y mecanismos para el cargamento de los cereales en barcos fluviales. La prosperidad fue enorme, durando hasta la guerra sueco-polaca de mediados del siglo XVII, que arruinaría Polonia de forma dramática. En un solo año llegaron a Gdànsk cerca de doscientos navíos procedentes de los Países Bajos, aparte de las mercancías que habitualmente transportaban los navíos de Gdànsk. Por entonces, España estaba interesada en lo que pasaba en el Báltico, si bien no puede decirse de ninguna manera que la zona estuviese pacificada, puesto que, en realidad, era el campo de rivalidad entre Suecia y Dinamarca. También tuvieron intereses comerciales y políticos en dicha área Inglaterra, Rusia y Polonia. De esta forma, las guerras dificultarían el comercio y en particular el abastecimiento de los Países Bajos. En 1564, cuando Dinamarca bloqueó el Estrecho de Sund, el precio de los cereales aumentó en Amsterdam el 100\%. Durante algún tiempo, España consideraría la posibilidad de establecer una base marítima en el Báltico que protegiera el comercio con los Países Bajos, más esto no pudo ser llevado a cabo. Sin embargo, España, durante la guerra que sostuvo con las Provincias Unidas, gestionaría la ayuda polaca, proponiendo al rey Stefan Bathory la compra de todos los cereales que hasta entonces iban a los mercados de los Países Bajos, pero tampoco pudo ser realizado: la burocracia discurría tan lentamente que el proyecto debió ser finalmente abandonado.

Sabemos también que, en el siglo XVI y primera mitad del XVII, hasta la invasión sueca que, según se dijo, arruinaría Polonia, Gdànsk mantuvo contactos con puertos españoles, y sus barcos llegarían incluso hasta Cádiz y otros puertos de Andalucía. Pero estos asuntos, hasta el presente, no han sido estudiados todo lo que se merecen.

Volviendo a las relaciones diplomáticas, conviene añadir como complemento, que también existieron embajadas españolas en Polonia, no obstante su carácter esporádico y, por tanto, de corta duración. Se limitaron únicamente a tratar temas del momento, como obtención del apoyo polaco para la candidatura de Carlos I al Imperio, o a prestar ayu- 
da (en tiempos de Felipe II) al candidato austríaco al trono polaco tras la muerte de Segismundo Augusto en 1572, circunstancia en que la corona polaca pasaría de ser hereditaria a electiva. Las embajadas se preocuparon también de arreglar asuntos extraordinariamente importantes para el mundo cristiano, como la unidad frente a los turcos o el apoyo a Polonia con fuerzas militares españolas en sus guerras con los turcos. Sin embargo, ninguna de estas gestiones llegaría a prosperar: la excesiva distancia entre los dos países haría imposible acciones en común contra el Imperio Otomano, aunque éstas se redujesen al campo diplomático. Así, pues, a dichos embajadores, más que españoles, de nacionalidad flamenca o austríaca, se les recibiría, a la manera polaca, de forma muy ostentosa. Las opiniones de estos legados fueron bastante elogiosas, sin dar la impresión de Polonia como un país exótico. Les asombraba el paisaje, tan diferente del español, y también el régimen político (Polonia era una república gobernada por la nobleza).

El siglo XVI puede considerarse como una época de oro, tanto para Polonia (y así se la llama) como para España. Este concepto se refiere no sólo a la posición del Estado, que alcanzaría en este tiempo su cénit, sino también al gran desarrollo de la literatura, el arte y la cultura en general. Además de las relaciones diplomáticas entre los dos países, existieron también otras de tipo cultural, aunque de carácter esporádico e indirecto. Polonia, en aquella época, fue muy receptiva, acogiendo todo lo bueno que venía del exterior en los planos intelectual y material. Por lo que se refiere a España, estos contactos estuvieron dificultados por la magnitud de la distancia y la escasez de relaciones directas entre ambos países. No existieron contactos a nivel universitario: los estudiantes españoles no llegaron a la universidad de Cracovia, a pesar del alto nivel de ésta durante este siglo. De la misma manera, los polacos no vinieron a estudiar a España, eligiendo en cambio universidades más próximas, bien alemanas o italianas. Así pues, los contactos culturales y científicos tuvieron lugar, justamente, en las universidades italianas y, sobre todo, en las de Padua y Bolonia. Allí conocieron los estudiosos polacos los éxitos obtenidos por la ciencia española, así como sus autores, esforzándose en hacer venir a los mejores de ellos a la universidad de Cracovia y a la Corte, ubicada en la misma ciudad. La universidad fue un verdadero foco de humanismo, de corte italiano. Los emigrantes españoles se sintieron allí a gusto y residieron en ella durante largos años.

Conocemos el nombre de dos de ellos. El primero se llamaba García Quadros y era de Sevilla. Fue catedrático de Derecho en la universidad de Cracovia entre los años 1510 y 1516. Había llegado a Polonia, procedente de Bolonia, gracias a la invitación del eminente humanista polaco y amigo del papa León X, Erasmo Ciolek, obispo de Plock, co- 
nocido también como notable diplomático y embajador en Italia y Alemania. Quadros, que moriría años después en el Vístula, compaginó en el país eslavo el trabajo universitario con la diplomacia. A este último respecto llegaría a consejero en la corte del rey de Polonia, tomando parte en las negociaciones de este país con la Orden. Teutónica de Prusia, en diversos litigios entre ambos. Quadros publicaría en Polonia una serie de trabajos científicos sobre Derecho, impresos en Cracovia. Fue muy conócido en este país y su actividad en él alcanzó un gran reconocimiento.

El otro emigrante fue Pedro Ruiz de Moros, apellidado en Polonia «Rojzjusz» y denominado «El doctor español», conocido de todos los polacos que han pasado por la Enseñanza Secundaria. Ruiz de Moros llegará, incluso, a ser protagonista de uno de los epigramas del eminente poeta polaco Kochanowski, que fue contemporáneo suyo y lo conocía muy bien. En dicho epigrama, el poeta se refiere al doctor como a un jovial compañero al que le gusta el vino español (los vinos españoles eran ya conocidos en Polonia), el cual, yéndose a dormir temprano porque estaba harto de beber, fue acosado por sus compañeros que le llevaban otro jarro. El doctor no quiso dejarles entrar, pero ellos, forzando la puerta, penetraron en el interior de su habitación. Al día siguiente, el español se quejaba de que, habiéndose ido a acostar sereno, se había levantado borracho.

A Ruiz lo mencionan también otros poetas polacos contemporáneos en sus obras, siempre afectuosamente y con respeto, presentándolo como un hombre de conducta virtuosa. Pero Ruiz, no solamente acudió a Polonia para vivir alegremente, sino que ejerció en la universidad de Cracovia como uno de los más eminentes catedráticos de Derecho Romano con que este centro contó. Hay que subrayar, sin embargo, que anteriormente Moros ocupaba un cargo de carácter jurídico en Milán, lo cual no le impidió aprovechar la invitación para marchar a Polonia, decisión que probablemente sería tomada más por los contactos establecidos con polacos en la universidad de Bolonia, donde se doctoraría, que obedeciendo a instigaciones para trasladarse a este país. Más tarde, tuvo ocasión de viajar a Viena, a donde le llamaría el emperador Fernando I, pero el rey de Polonia, Segismundo Augusto, se lo impidió.

Ruiz debió ser muy estimado en Polonia, pues tampoco conseguiría trasladarse al Tribunal de la Rota en Roma en 1561, porque, aunque no conocemos muy bien los hechos, alguien puso obstáculos al viaje. Así, pues, el español permanecería en Polonia, y más precisamente en Lituania, hasta su muerte en 1571 . Desde 1552 había vivido en Vilna (prácticamente la segunda capital de Polonia) donde ejercería diferentes dignidades eclesiásticas. Ruiz, como hombre de ciencia y eminente ex- 
perto en Derecho romano y polaco, escribió y publicó en latín numerosas obras. A este respecto conviene citar sus «Decisiones de rebus in Sacro Auditorio Lithuanico", editada en Cracovia el año 1563, que obtendría un gran éxito en toda Europa, siendo reimpresa en varios países del continente. Aún en el siglo XVIII continuaron publicándose en Polonia sus obras.

Las opiniones de Ruiz tuvieron una gran influencia en los tratadistas políticos de Polonia del siglo XVI, especialmente en Andrzej Frycz Modrzewski con su obra "De Republica emendanda». El término «República" se refería a Polonia, que por aquel entonces era una democracia nobiliaria, en tanto que "emendanda" hacía alusión a las reformas sociales y políticas que era necesario introducir en Polonia para evitar una mala dirección de los asuntos públicos. Modrzewski fue también influido por las obras de Juan Luis Vives, tomando de él la idea de la importancia de la instrucción pública, que debía estar controlada por el Estado. Por la obra de Modrzewski también se interesaron en España: uno de sus capítulos, "De bello", fue incluso traducido al castellano, si bien nunca se publicó.

Ruiz no solamente fue autor de obras políticas, sino que se ocupó además de una literatura más liviana: escribió así en diversas ocasiones panegíricos dedicados al monarca y a hombres adinerados, oficio que siempre le fue rentable, puesto que por estos poemas recibía generosas gratificaciones. Fue autor también de poemas satíricos, uno de los cuales, "in Lithuanicam peregrinationem", pasó a la historia de la literatura polaca como un ejemplo de esta poesía macarrónica (de versos de carácter jocoso escritos en latín con las desinencias de las palabras en polaco, lo que producía grandes efectos cómicos que provocaban la diversión de muchos poetas, entre ellos el ya mencionado Kochanowski).

No solamente llegó a Polonia procedente de España literatura política, sino también, y sobre todo, espiritual, divulgada por las distintas órdenes religiosas, muchos de cuyos conventos fueron fundados por españoles. Los polacos siempre instalaron en su país nuevas congregaciones de buena gana, que todavía hoy son muy numerosas, no existiendo hoy día muchas de ellas más que en Polonia o Italia. Estas nuevas órdenes eran introducidas por extranjeros, y solamente con posterioridad ingresaban en las mismas súbditos de Polonia. Así sucedió en los siglos XVI y XVII: los jesuitas se fundaron en 1534, y ya en 1556 y 1557 residió en Polonia uno de los compañeros de San Ignacio de Loyola, Alonso Salmerón, alojándose en la mansión del nuncio papal Lippomano. Durante el primer período de la estancia de los jesuitas en Polonia, la mayoría fueron españoles, y su desarrollo en el país fue muy rápido, controlando casi todas las escuelas secundarias y creando numerosos cole- 
gios, uno de los cuales, el de Vilna, fue muy pronto transformado en universidad. Entre estos primeros jesuitas residentes en Polonia se encuentran eminentes teólogos españoles como Garcías Alabiani y Ortiz.

En 1605 se estableció en Polonia un grupo de carmelitas descalzos que se dirigían a Persia como misioneros. Mientras recorrían Polonia se detuvieron en Cracovia y fundaron aquí su primer monasterio en este país eslavo, renunciando a proseguir su ruta hacia Persia. Este grupo estaba formado por tres españoles y un napolitano, y la orden arraigó muy pronto en Polonia: doce años más tarde ya tenían tantos monasterios, que Polonia fue convertida en una provincia de dicha orden.

Por lo que se refiere a la literatura traída por estas órdenes españolas a Polonia, hay que decir que las obras teológicas y especialmente místicas tuvieron por su propia naturaleza una difusión muy restringida, que se limitó solamente a los religiosos, no divulgándose entre los lectores laicos. Pero gracias a las órdenes religiosas, los eclesiásticos polacos tuvieron la ocasión de conocer a los grandes místicos españoles, como fray Luis de Granada, San Juan de la Cruz y Santa Teresa de Jesús (más conocida en Polonia como Santa Teresa de Avila). Las obras de estos dos santos fueron, además, traducidas al polaco, y todavía continúan existiendo versiones tan leídas hoy como en el siglo XVII. Se advierten también influencias de la poesía mística española en la literatura polaca, pero aquélla, como en el caso de la literatura religiosa, fue muy importante. Una divulgación más amplia de este tipo de literatura sólo hubiera sido posible de no haber sido frenada por el propio carácter polaco, donde no existe una inclinación notable al misticismo, ni a la introversión, ni a la vida religiosa profunda.

Pero, junto a los libros religiosos, con las órdenes, y especialmente con los jesuitas, llegarán también obras de carácter económico e historiográfico escritas por miembros de la Compañía de Jesús. Se difundió sobre todo el "De rege» del padre Juan de Mariana, citado por los escritores políticos polacos del siglo XVIII. Sin embargo, la literatura política española no arraigó plenamente: los sistemas políticos existentes en ambos países eran diametralmente opuestos: en Polonia, el absolutismo era generalmente odiado.

Estas diferencias en cuanto al régimen político, y especialmente el temor al absolutismo por parte de la nobleza polaca, así como el ambiente de tolerancia religiosa, convertida en regla hasta los años sesenta del siglo XVII y mantenida "de facto» con posterioridad, provocaron que las relaciones polaco-españolas se debilitaran de forma muy considerable y hasta cesaran, durante más de un siglo, hasta mediados del siglo XVIII; incluso las guerras de Polonia contra Turquía, conducidas por el rey Juan III Sobieski, con victorias tan importantes como el so- 
corro de Viena de 1683, estuvieron inspiradas por un cierto interés político. Las diferencias políticas y la convicción cada vez mayor de la nobleza polaca de que el sistema político y social de su país era el ideal, además de estar sancionado por Dios, así como la creencia sobre que nada podía ser aprendido de nadie, hacían que la opinión polaca con respecto a España no fuera buena. Se consideraba a este país un estado absoluto y no se tenía una buena imagen de la pacificación llevada a cabo por los españoles en los Países Bajos, incluso en el siglo XVIII. El sistema absoluto del gobierno era incesantemente comparado a la «libertad de oro" polaca, que por lo demás perdería a Polonia. El carácter de los españoles tenía mala fama, siendo considerados de una gran soberbia. Los comerciantes de Gdànsk se quejaban de que eran mal acogidos en los puertos españoles, al igual que de la avaricia y brutalidad de sus funcionarios. Como contrapartida podemos decir que parecidas opiniones se propagaban en relación con otros países de Europa (Francia, Italia, Inglaterra y Países Bajos). Por otro lado, la acción colonizadora de España en América era observada con atención, encontrándose en ella un ejemplo y estímulo para una acción similar emprendida por los polacos en Ucrania.

Cuando los contactos desaparecieron, en España se forjó una imagen de Polonia como un país lejano, distante y exótico, incluso entre los hombres cultivados. Así lo vemos en las obras de Calderón, quien, por ejemplo, en "La vida es sueño", situó la capital de Polonia sobre el mar, y dio a su rey y a sus sirvientes apellidos rusos. También Baltasar Gracián, en su obra "El Criticón", describiría a Polonia en términos falseados. Pero no debemos asombrarnos: la misma falta de conocimiento geográfico tenía Shakespeare con respecto a aquella parte de Europa.

Todo ello tuvo sus consecuencias en el plano cultural. A Polonia no llegaría el teatro español, siendo en ella sustituido por el italiano, lo que resulta un tanto extraño dado que el teatro polaco fue siempre muy vivo y se representó habitualmente en los colegios jesuitas. Ignoramos, así pues, por qué la orden de San Ignacio no importó a Polonia las obras de los escritores españoles, incluido el propio Cervantes. Este sería conocido en el país muy tardíamente (en 1786) y todavía no de forma directa, sino a través de su adaptación al francés. En ese mismo tiempo se tradujo otra obra de Cervantes («La Galatea»), al igual que los dramas de Rojas y "El alcalde de Zalamea» de Calderón. Todo esto se llevó a cabo a través de las susodichas traducciones francesas y alemanas. Durante el Siglo de las Luces, el Despotismo Ilustrado, muy fuerte en Polonia como movimiento cultural más que político, pondría obstáculos a una eventual aproximación polaco-española. Como sabemos, para los hombres y escritores de este movimiento, España era símbolo de una 
época ya periclitada, subrayando su atraso en todas las esferas y su total obediencia a la Iglesia; por lo demás, algo similar se dijo y se reprochó a Polonia. Pero aquí, los escritores políticos del Despotismo Ilustrado utilizaron tales críticas a fin de demostrar los malos efectos del atraso de su país y tomarlos como base de sus pretendidas reformas. Durante el siglo XVIII se introdujo ya un sistema de representación diplomática estable con verdadero rango de embajada y legaciones. En cuanto a Polonia, ésta se iniciaría en 1790, siendo el último legado español en este país Domingo de Iriarte, pues cinco años más tarde Polonia dejaría de ser un estado independiente. Dicho embajador fue un gran amigo de los emigrantes polacos que lucharon por la restitución de Polonia. Por lo que respecta a ésta, su representación con carácter estable en Madrid se inició antes, en 1764, siendo su último embajador Kajetan Zbyszewski, encargado de Asuntos Exteriores.

El siglo XIX no fue tiempo de contactos políticos, ya que éstos no pudieron tener lugar por parte de Polonia. Fueron tiempos de relaciones fundamentalmente literarias, que exigirían un tratamiento separado que no podemos hacer aquí. De parte de España aumentaría el interés sobre Polonia, sus hombres, desgracias políticas, decadencia y sublevaciones, lo que estimularía el Romanticismo (que se prolongó en España durante mucho tiempo) al proclamar que cada nación es un organismo vivo, con su espíritu peculiar, que no puede ser violado ni extinguido. Por esta época se introdujeron en España bastantes obras de carácter científico y literario (poesías y cuentos). De esta aproximación nació entre ambas naciones un hilo de simpatía que llega hasta nuestros días: pero como antes he dicho, se trata ya de un capítulo aparte que exige mayores investigaciones, sobre todo en el campo de la literatura.

Esta aproximación fue también posible gracias a la historiografía, y si en lo que fue dicho han existido muchos elementos negativos, no cabe duda de que éstos pudieron 'ser compensados gracias a la obra de un gran creador de la ciencia histórica polaca, Joachin Lelewel. En 1820 este historiador escribiría un pequeño libro, más bien un artículo, titulado "Historyczna Parallela Hiszpaniz Polska XVI, XVII, XVIII Wieku" (Paralelos de la Historia española y polaca en los siglos XVI, XVII y XVIII). Este libro apareció en Varsovia en 1831, teniendo en el siglo XIX dos ediciones; actualmente ha sido incluido en la edición de las obras completas de Lelewel. Existen, además, otras ediciones en alemán (Stuttgart, 1834) y en la "Revue du Nord» (París, 1835). Se hicieron también dos traducciones, una italiana que no fue publicada, y otra española que en mi opinión tampoco se publicó. Lelewel llevó a cabo un análisis muy preciso de las semejanzas entre ambos países, siglo a siglo y acontecimiento a acontecimiento, llegando a la siguiente conclusión: 
"Se puede decir que, a fines del siglo XVI, cuando, de una parte, se restablece Francia, y de otra Moscovia, España y Polonia se convierten en grandes estados. Durante este mismo siglo ambos países son preponderantes. En el centro de Europa, el Sacro Imperio Germánico era la sede de numerosos cristianos separados de Roma. Donde se hablaba la lengua alemana, existió la confesión protestante. España, de un lado, Polonia, de otro, permanecieron fieles a Roma, católicos, gobernando sobre una parte importante de los alemanes. España y Polonia, con escasa diferencia de tiempo, casi contemporáneamente, abandonan la cumbre política de su grandeza para descender. Ambos perderán la mayor parte de los países alemanes donde gobernaban, ambos verán también reducirse sus fronteras, ambos países serán destruidos, debilitados y, en fin, entumecidos por la impotencia, llegarían a ser un juguete en manos de sus vecinos. Para ambos, pues, estaba preparada una idéntica decadencia duradera".

Los paralelismos establecidos por Lelewel no sólo se refieren a acontecimientos políticos, sino también a asuntos sociales. A pesar de las grandes diferencias existentes en el sistema político, los parecidos entre la nobleza española y polaca son evidentes. Un noble de Polonia, al igual que un hidalgo español, creía que la única profesión que podía ejecutar sin detrimento de su honor era un servicio público o militar, o dignidades eclesiásticas. Cualquier otra profesión era excluida e implicaba la pérdida de la condición nobiliaria. El orgullo, frecuentemente, fue uno de los principales atributos de esta clase social en ambas naciones.

Pero estas son cuestiones del pasado. En cuanto a nuestro tiempo, queda mucho por hacer en Polonia para conocer España. No existe en polaco una historia de España. No hay tampoco monografías. Sería necesario una edición completa de los relatos de los diplomáticos españoles en Polonia y polacos en España. No se han estudiado las relaciones comerciales y prácticamente no sabemos nada de ellas, tan sólo que existieron. Quizás el futuro se ocupe de todos estos problemas, otrora tan abandonados. 